\title{
WestVirginiaUniversity
}

THE RESEARCH REPOSITORY @ WVU

Graduate Theses, Dissertations, and Problem Reports

2005

\section{Gossip as an interpersonal communication phenomenon}

Elycia M. Taylor

West Virginia University

Follow this and additional works at: https://researchrepository.wvu.edu/etd

\section{Recommended Citation}

Taylor, Elycia M., "Gossip as an interpersonal communication phenomenon" (2005). Graduate Theses, Dissertations, and Problem Reports. 860.

https://researchrepository.wvu.edu/etd/860

This Thesis is protected by copyright and/or related rights. It has been brought to you by the The Research Repository @ WVU with permission from the rights-holder(s). You are free to use this Thesis in any way that is permitted by the copyright and related rights legislation that applies to your use. For other uses you must obtain permission from the rights-holder(s) directly, unless additional rights are indicated by a Creative Commons license in the record and/ or on the work itself. This Thesis has been accepted for inclusion in WVU Graduate Theses, Dissertations, and Problem Reports collection by an authorized administrator of The Research Repository @ WVU. For more information, please contact researchrepository@mail.wvu.edu. 
Gossip as an Interpersonal Communication Phenomenon

Elycia M. Taylor

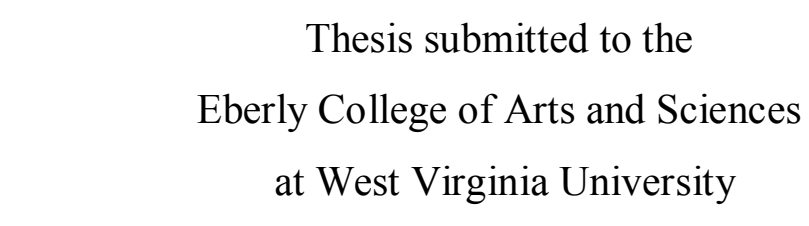

in partial fulfillment of the requirements for the degree of

Master of Arts in Communication Studies

Keith D. Weber, Ph.D., Chair

Matthew M. Martin, Ph.D.

Scott A. Myers, Ph.D.

Department of Communication Studies

Morgantown, West Virginia

2005

Keywords: Gossip, Validity, Indirect Interpersonal Aggression, Machiavellianism

(C) Copyright 2005 Elycia M. Taylor 


\section{Abstract \\ Gossip as an Interpersonal Communication Phenomenon}

Elycia M. Taylor

Two studies were conducted for the purpose of validating Foster's (2004) Gossip Functions Questionnaire (GFQ) which measures the reasons why people gossip (i.e., the functions of gossip). The GFQ originally consisted of four subscales that measured the functions of gossip: information, entertainment, friendship, and influence. In Study One, an exploratory factor analysis failed to reveal the four subscales Foster originally conceptualized. However, three factors were apparent that seemed to measure three separate functions of gossip: trivial gossip, influential gossip, and behavioral guidance gossip. In Study Two, a confirmatory factor analysis of a second data set failed to validate the 3-factor Gossip Functions Questionnaire. It was also proposed that the GFQ would be related to indirect interpersonal aggression, Machiavellianism, and tendency to gossip. The data from Study Two indicated that the 3-factor Gossip Functions Questionnaire was, in fact, significantly positively related to each of the variables above. 
Table of Contents

II.TABLE OF CONTENTS ..............................................................

III.REVIEW OF LITERATURE .................................................

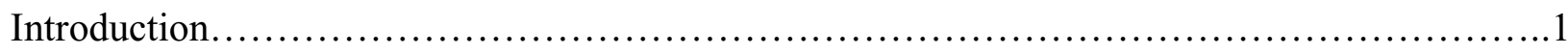

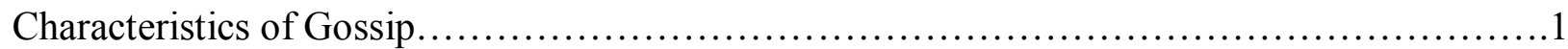

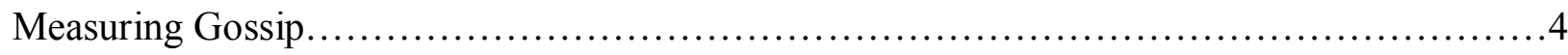

Rationale....................................................................... 8

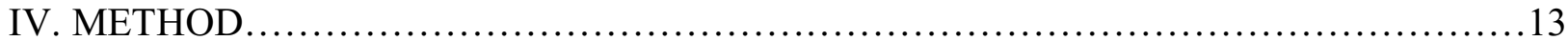



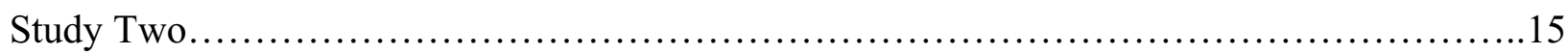

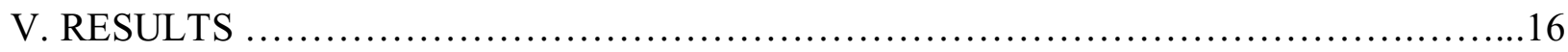

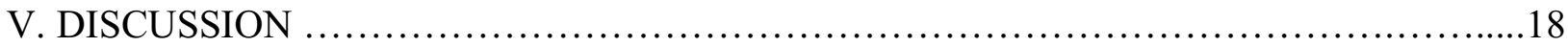

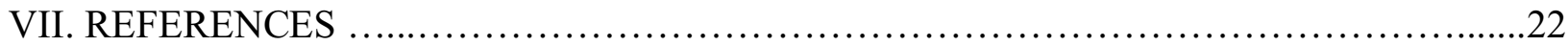

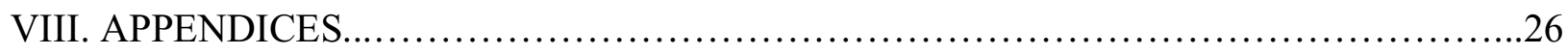

Appendix A (Factor Loadings of the 3-Factor GFQ) ..........................................26

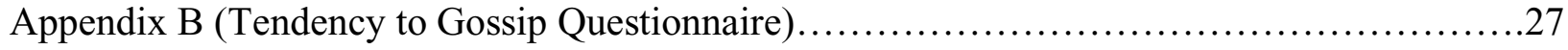

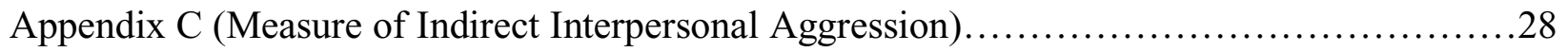

Appendix D (Machiavellianism Scale).............................................29 


\section{Gossip as an Interpersonal Communication Phenomenon}

According to Dunbar, Duncan, and Marriott (1997), communication about social topics comprises a vast amount of an individual's interpersonal interactions. In fact, they estimate that approximately $65 \%$ of communication centers around social topics, which also is referred to as gossip. Because gossip is so prevalent within communication, it would seem to be an inevitable area for communication scholars to research. However, the existing body of literature conducted on gossip within the field of Communication is sparse, possibly due to the lack of validated instruments measuring the gossip concept. With this in mind, this study will add to the literature concerning the possibly inevitable human phenomenon of gossip. To do so, this study will examine the validity of Foster's (2004) Gossip Functions Questionnaire (GFQ). Foster's instrument measures four social functions of gossip: (a) information, (b) entertainment, (c) friendship, and (d) influence. This study will examine the validity of the GFQ through an exploratory factor analysis, a confirmatory factor analysis, and testing the GFQ's relationship with other theoretically related variables (i.e., indirect interpersonal aggression, Machiavellianism, tendency to gossip).

\section{Characteristics of Gossip}

\section{Definition of Gossip}

The definition of gossip has taken many forms; however, the core definition seems to be overarching: casual conversation about social topics (Dunbar, 2004). Researchers have attempted to narrow this definition by assuming that gossip can be labeled as positive or negative communication about absent third parties (Foster, 2004; Kuttler, Parker, \& La Greca, 2002). Although there are specific situations where the third party may be present, Kuttler et al. (2002) asserted that those situations are rare and may be described simply as public disclosure or 
ridicule, not gossip. Nevo and Nevo (1993) defined gossip as communication about an absent third party, but without a conscious effort to disseminate specific or important information. Therefore, for the purpose of this study, gossip will be defined as an evaluative, casual conversation about an absent third party.

Types of Gossip

Because gossip is defined as evaluative (positive or negative) conversation, a clear distinction should be drawn between "positive gossip" and "negative gossip" (Turner, Mazur, Wendel, \& Winslow, 2003). "Positive gossip" is information about socially approved behavior. In this case, gossip acts as a positive social sanction (Levin, Mody-Desbareau, \& Arluke, 1988). People may also use "negative gossip" which acts as a negative social sanction, usually dealing with socially inappropriate behavior (Levin et al., 1988). Negative gossip is malicious, for it concerns absent third parties that cannot defend themselves. Both parties in the gossip must "suspend their normal standards of credulousness" (Nicholson, 2001, p.64) while they talk negatively about someone behind their back, therefore, making negative gossip extremely objectionable to most people. In contrast, "positive gossip" can, as mentioned before, act as a positive social sanction, bringing power and praise to the absent third party. Nonetheless, Turner et al. (2003) asserted that gossip is still associated with a negative paradigm, regardless of its positivity or negativity.

Nevo and Nevo (1993) identified a number of additional types of gossip other than simply positive or negative gossip. They stated that individuals gossip about others' achievements, physical appearance, and personal lives. Additionally, individuals may partake in intellectual gossip, such as reading gossip columns or biographies of famous people (Levin et al., 1988; Nevo \& Nevo, 1993). 


\section{Gossip versus Rumor}

Although gossip has been defined and categorized into types within the literature, the terms "gossip" and "rumor" are still used interchangeably when they are two separate communication phenomenon. This distinction is important and should be addressed for the sake of decreasing confusion in the literature. Rumor, as suggested by Rosnow and Fine (1976), is frequently a synonym for negative gossip when there are three important differences that clearly delineate rumor from gossip.

First, Cooley (1962) defined rumor as communication about events, whereas, gossip is defined as communication about people. Rosnow and Fine (1976) stated that rumor is simply information that is necessary or imminent that is communicated to another. Gossip, on the other hand, is small talk or "chit chat", about other people, without obligation or urgency.

Second, gossip differs from rumor in that rumor deals with differences in the motivation for the communication. Rumor occurs, most often, as a need for clarification, closure, or filling an informational void (Rosnow \& Fine, 1976). This is different from gossip, which is thought to fill a character void. Gossip is motivated by ego and the need for status (Rosnow \& Fine, 1976). If this is true, then gossip can be viewed as being source motivated from a communication perspective, while rumor can be described as receiver based. Gossip seems to be driven by the source's ego and reach for status. Rumor, on the other hand, focuses on the receiver's lack of knowledge. Gossip is communication that takes place primarily for the source's benefit. While rumor implies that the source provides the information to the receiver, the receiver is more motivated to understand and use the information.

Third, rumor's evolution and termination progresses through stages and patterns (Hovland \& Weiss, 1951, Knapp, 1944, Rosnow \& Fine, 1976), whereas gossip does not 
progress through similar stages or patterns. It is possible that rumor has received more attention in the research community because it is easier to study through its stages and divisions (Wert \& Salovey, 2004). However, it is just as likely that these stages and patterns have been uncovered because rumor has had more attention with regard to research. Nevertheless, it is still true that the functions of rumor are developed and validated more extensively than the functions of gossip.

In summary, gossip and rumor are differentiated in three ways. Rumor concerns necessary information about events. Gossip is communication that concerns information about an absent person. Rumor is communication driven by the receiver's desire for important information, and essential to filling an informational void. Gossip is communication driven by the source's desire of status, and seems to fill a character void for the source. Finally, rumor has been conceptually defined and researched with specific stages and patterns while little attention has been focused on research concerning the conceptualization of gossip.

\section{Measuring Gossip}

The number of instruments used to measure topics related to gossip is quite sparse. Only two instruments exist in the literature concerning gossip: The Tendency to Gossip Questionnaire developed by Nevo and Nevo (1993) and the Gossip Functions Questionnaire developed by Foster (2004).

\section{Tendency to Gossip}

The tendency or propensity to gossip is a psychological disposition that guides individuals when they choose to talk or not talk about an absent third party (Nevo \& Nevo, 1993). Because gossip provides status and entertainment for some individuals, these individuals may be more prone to gossip since they do not see it as a negative activity as it is simply used as 
personal benefit (Nevo, Nevo, \& Derech-Zehavi, 1994).

A problem arises when examining self-perceptions of the use of gossip. Humans strive for social desirability, so gossip is usually hard to measure since it is considered non-desirable. Nevo and Nevo (1993) constructed the Tendency to Gossip Questionnaire (TGQ) to measure the propensity to gossip. They created 20 items in order to measure a person's tendency to gossip. Within these questions they tried to curb social desirability. Although the possibility of social desirability bias still remains, the measure has been used and validated in a number of previous studies (Foster, 2004, Nevo \& Nevo, 1993, Nevo et al., 1994, Turner et al., 2003). Individuals' tendency to gossip is related to their vocational interests. Nevo and Nevo (1993) found that subjects with people-oriented vocational interests showed a higher tendency to gossip (i.e., service, art, business). Turner et al. (2003) found that the TGQ was negatively related to liking, trust, and expertise of the source of the gossip.

Previous research has also found a relationship between gender and gossip. In most cases, individuals who are feminine have a higher tendency to gossip than individuals who are more masculine (Kuttler et al., 2002; Nevo et al., 1994; Nevo \& Nevo, 1993; Rysman, 1977).

\section{Functions of Gossip}

Empirical studies have been conducted to categorize the reasons why people gossip (i.e., the functions of gossip). The sparse amount of literature on the functions of gossip has primarily centered on four social functions that are based in social exchange theories (Foster, 2004). These functions are information, friendship, influence, and entertainment (Foster, 2004; Stirling, 1956) and are rooted in the assumption that gossip is a means of communicating information and strengthening in-group control sanctions, all of which increase solidarity of the group (Stirling, 1956). Additionally, Stirling explained that gossip is a way individuals verbalize pent-up 
aggression.

Foster (2004) developed an instrument measuring the functions of gossip first addressed by Stirling (1956). The Gossip Functions Questionnaire (GFQ) differentiates these functions of gossip in a quantitative measure that can be used for survey research (Foster, 2004). The GFQ consists of 24 statements, six statements for each of the four subscales: (a) information, (b) entertainment, (c) friendship, and (d) influence.

Information. The first function of gossip is simply when the sender disseminates information to the receiver. The interaction occurs when there is unequal knowledge between the participants and the sender spreads the information to the receiver(s) who were uninformed (Bergmann, 1993). This type of informational communication should not be confused with rumor. As explained above, this type of informational communication is not composed of information concerning events. The informational function of gossip concerns the spreading of information concerning absent third parties.

Entertainment. The second function of gossip explains how pleasure can be derived from gossip not only after the interaction takes place, but also as the actual function of gossip. Many communicators simply pass time gossiping or storytelling (Foster, 2004). However, the entertainment function does not apply to all situations. Because gossip is situational, it is hard to explain why each separate situation is considered "fun" or "rewarding" (Spacks, 1982).

Friendship. The third function of gossip explains how sharing gossip is a way to build friendship by bringing groups or dyads together and establishing boundaries to distinguish “insiders” from “outsiders (Foster, 2004). Groups often use gossip to deliberately exclude outsiders and to build their own inner network of shared information (Dunbar, 2004), which may explain why gossip is more likely to happen between already established friends than between 
acquaintances (Bergmann, 1993).

Influence. The final function of gossip is also used as a function to maintain social interaction. It is an influential control of social norms within each context (Dunbar, 2004). With the occurrence of gossip comes an inevitable interference with the receivers' impressionmanagement; the receivers are forced to change their impression of the target person of the gossip (Foster, 2004). Again, groups use this function of gossip as a type of maintenance within the group. Because groups will always internally generate some type of leader, gossip is used as a function to produce this leader, restrict freedom and eccentricities, and maintain leadership and conformity. Although gossip can be positive, this function of gossip certainly contributes to the criticism of this type of communication (Foster, 2004).

\section{Measurement Issues}

There are a number of issues that arise when looking at the instruments used in gossip research. As mentioned before, not only is literature concerning gossip sparse overall, there are only two instruments that have been utilized in the measurement of gossip. The TGQ focuses on the specific personality trait of individuals' propensity to gossip and the GFQ measures the reasons why people gossip.

The TGQ has been used and studied in relation to other variables such as liking, trust, vocation, and gender (Nevo \& Nevo, 1993; Nevo et al., 1994; Turner et al., 2003). However, the GFQ has only been addressed in one publication (Foster, 2004). In reviewing the seminal piece in which the GFQ was published, a number of concerns arise about the conceptualization and operationalization of the scale. Specifically, Foster does not fully explain the process involved in constructing his scale and the scale items. This raises concerns over the content validity of the scale. It is unclear how Foster derived these four functions. According to this seminal piece, 
Foster based his four functions on the work of Stirling (1956). However, while Stirling proposed there are different uses or functions of gossip in general, she does not separate her ideas into the four specific functions Foster has suggested. Because of this, the efficacy of Foster's 4-function model should be questioned. Second, even if the assumption of the four functions of gossip is correct, the items of the GFQ may not be representative of the underlying concept of each subscale. The relationship between the specific items and the function that they are supposed to represent needs to be validated. Third, Foster provided reliabilities for each subscale of the GFQ. According to Singleton and Straits (1999), an internal reliability below 0.70 is substandard and should be questioned. Foster found that at least one of the subscales had a substandard reliability (i.e., influence, 0.64). The GFQ has yet to be validated, making it a questionable measure to use.

\section{Rationale}

To further the chance of predicting and explaining the gossip phenomenon, the topic must be explored from a quantitative perspective. If gossip is to be studied from such a perspective, valid measurement instruments must be available. It is unsure if Foster (2004) has constructed a valid operationalization of the functions of gossip. Therefore, the first step in providing support for the content validity of any measure of gossip is through exploratory factor analysis techniques (Khattree \& Naik, 2000). Hatcher (1994) explained that an exploratory factor analysis is appropriate when there is a need to identify the number and nature of the underlying factors in a given set of data. Foster (2004) asserted that his GFQ is comprised of four factors. Although Foster (2004) defined these factors, he gives no empirical evidence to support them. By performing an exploratory factor analysis, this study could provide the support necessary for Foster's (2004) assertions. Therefore, the following hypothesis is offered:

H1: The GFQ is composed of four dimensions. 
Assuming the exploratory factor analysis provides an interpretable factor structure, Khattree and Naik (2000) asserted that two additional steps are necessary to validate an instrument. The first additional step is to collect a separate data set and conduct a confirmatory factor analysis. A confirmatory factor analysis is a factor analysis in which the factor structure is hypothesized. In this manner, the researcher attempts to confirm that the hypothesized factor model is the correct model to adopt (Khattree \& Naik, 2000). Thompson and Daniel (1996) supported this assumption when they stated, "CFA can readily be used to test rival models and to quantify the fit to each rival model...testing multiple, plausible models does yield stronger evidence regarding validity" (p.204).

The second additional step to further validate the GFQ is to provide evidence of construct validity. One manner in which to verify the construct validity of a measure is by testing its relationship with other theoretically related variables (Frey, Botan, \& Kreps, 2000). Two such variables that should be related to the GFQ are indirect interpersonal aggression and Machiavellianism.

\section{Indirect Interpersonal Aggression}

Beatty, Valencic, Rudd, and Dobos (1999) conceptualized indirect interpersonal aggression as "a predisposition to harm other people without engaging in face-to-face interaction" (p. 105). Previous research has found that indirect interpersonal aggression is positively related to psychoticism, verbal aggressiveness, assertiveness, and Machiavellianism (Beatty et al., 1999; Martin \& Valencic, 2002). Additionally, negative relationships have been reported between indirect interpersonal aggression and both cognitive flexibility (Chesebro \& Martin, 2003) and responsiveness (Martin \& Valencic, 2002).

Based on this research, a relationship should exist between gossip and an individual's 
amount of indirect interpersonal aggression use. Stirling (1956) stated that gossip is a way to verbalize pent-up aggression. Similarly, in their discussion of indirect interpersonal aggression, Beatty et al. (1999) described gossip as an example of indirect interpersonal aggression. The idea that gossip can be a form of indirect interpersonal aggression has also been addressed in studies completed by Foster and Rosnow (2005), Cayanus and Martin (2005), and Martin and Valencic (2002).

Because individuals use indirect interpersonal aggression to harm other people without face-to-face attack (Beatty et al., 1999), the functions of gossip should be used to negatively alter the way the receiver of the gossip feels about the absent third person. Therefore, the second hypothesis is offered:

H2: A positive relationship will exist between individuals' use of indirect interpersonal aggression and the functions of gossip.

\section{Machiavellianism}

Christie and Geis (1970) constructed an instrument measuring the extent to which a person uses manipulation and deceit for the purpose of receiving a desired response, which they labeled as Machiavellianism. Machiavellianism has grown to be a well-established concept in literature concerning personality and behavior. Machiavellians (Machs) are social manipulators who influence others for personal gain, without regard for the others' self-interest (Wilson, Near, \& Miller, 1996). High Machs have little involvement in their interpersonal relationships, and will do anything it takes within these relationships when it is to their advantage (Christie \& Geis, 1970; Mudrack \& Mason, 1995).

Christie and Geis (1970) asserted that Machiavellianism has four principle dimensions: a lack of affect in interpersonal relations, a lack of concern for conventional morality, low 
ideological commitment, and a lack of gross pathology. High Machs are individuals who exhibit characteristics such as affective detachment, intact reality contact, and manipulativeness. In other words, high Machs are successful manipulators, very cognitive, appear unemotional, and are not moved by their own constraints or past attitudes (Blumstein, 1973; Christie \& Geis, 1970). The same authors assert that low Machs fail at manipulation because of their strong emotional involvement with others.

Subsequent research has continued to use Christie and Geis's conceptualization of Machiavellianism. McHoskey (1995) found that Machiavellianism is related to narcissism, or a willingness to exploit others to obtain favors, admiration, or attention. Additionally, Lilienfeld (1996) found that antisocial practices were highly correlated with Machiavellianism.

Blumstein (1973) found that high Machs are successful manipulators and are able to put on whatever "face" necessary in the encounter to facilitate their task, even when an audience is present. Low Machs, on the other hand, become even more distant when asked to complete a bargaining task in front of an audience. Burgoon (1971) hypothesized that high Machs, with their abilities to improvise, will thrive in basic communication courses concerned with student participation, leadership, and group discussion. Burgoon's (1971) hypothesis was supported.

Widgery and Ruch (1981) examined high and low Machs as the receivers of manipulation. The authors were concerned with the extent of manipulativeness on both high and low Machs with regard to the physical attractiveness of the source. Overall, Widgery and Ruch (1981) found that, typically, the more the attractive source, the more persuasive the source was perceived. Additionally, they found that low Machs were greatly influenced by the sources attractiveness, while high Machs were not.

High Machs use communication as a tool of manipulation. Using self-reports, Falbo 
(1977) found that high Machs use strategies such as manipulating others' emotions and persuading others to do what they want. High Machs may even let the other person believe that the idea originated from the other person, possibly making the message more influential (Falbo, 1977).

High Machs are social manipulators that will do anything it takes to get what they want. Nicholson (2001) stated that those who gossip must suspend their morals or their credulousness. In order to get what they want, high Machs tend to have a lack of affect for others as well as a tendency to suspend their morality (Christine \& Geis, 1970). With this in mind, an assumption can be made that high Machs would be more willing to gossip, suspending their credulousness, as a means to manipulate others to achieve their self-profiting goal. The high-Mach will, most likely, use the functions of gossip to make the receiver of the gossip think or act the way that they want. Therefore, the following hypothesis is offered:

H3: A positive relationship will exist between individuals' level of Machiavellianism and the functions of gossip.

In addition to examining Indirect Interpersonal Aggression and Machiavellianism, a strong relationship between individuals' use of the functions of gossip and their overall tendency to use gossip would also be expected. Another way of testing construct validity is through consistency of different methods of measurement concerning the same underlying concept, or convergent validity. Singleton and Straits (1999) asserted that different measures of the same concept should be correlated. The Tendency to Gossip Questionnaire (TGQ) measures an individual's propensity to gossip. If individuals tend to gossip, their score on the TGQ should be positively related to their use of the functions of gossip. The more individuals gossip, the more they should use the gossip functions. Therefore the fourth hypothesis is offered: 
H4: A positive relationship will exist between individuals' tendency to gossip and the functions of gossip.

Method

To explore the hypotheses and answer the research question, two studies were conducted. The purpose of Study One was to collect data in order to determine the dimensionality of the GFQ through performing an exploratory factor analysis. The purpose of Study Two was to confirm the multi-dimensional structure of the GFQ that emerged from Study One, as well as to validate the scale in its entirety. This procedure is consistent with the recommendation provided by Thompson and Daniel (1996).

Study One

Participants. Participants for this study consisted of a convenience sample of 364 college students from a large mid-Atlantic university. Participation in the study was voluntary and responses were kept anonymous. The participants' demographic information was not collected in this study.

Measures. The 24-item Gossip Functions Questionnaire developed by Foster (2004) was distributed along with 32 additional items. The additional items resulted from two changes to the original scale. First, because individuals may have trouble admitting to gossip a social desirability bias may occur. Therefore, each item that used the term "gossip" was changed to "talking about an absent third party". To make an even number of items that used both phrases, each item that had a phrase similar to "talking about an absent third party" was then replicated to use the term "gossip." This resulted in the creation of an additional 24 items. Second, eight additional items were included in an attempt to increase the reliability of the subscales. These eight items were derived after a careful review of the gossip literature. 
The participants completed this five-point Likert-type scale that ranges from strongly disagree (1) to strongly agree (5). The 56-items were intended to represent the four functions of gossip reviewed earlier: 14 items for informational gossip, 14 items for friendship gossip, 14 items for entertainment gossip, and 14 items for influential gossip.

The responses to the 56 items were then subjected to an exploratory factor analysis. The criterion for the item retention was a primary loading of at least 0.50 , with no secondary loading over 0.40 . This factor analysis used a varimax rotation, which calls for an oblique factor rotation. A factor was deemed significant if it met the criteria established by Hatcher (1994). A factor needed to have a minimum eigenvalue of 1.0 , have three items with their primary loadings on that factor, and account for at least $5 \%$ of the variance of the total scale. The initial analysis resulted in a nine-factor solution.

Nine rounds of item reduction then were conducted. The first four rounds resulted in the deletion of 19 items as a result of low primary loadings which resulted in a six-factor solution. The second five rounds of item reduction resulted in the deletion of 13 items as a result of high secondary loadings which resulted in a 3 -factor solution. To keep the number of items equal in these three factors remaining, six additional items with the lowest factor loadings were deleted. Deleting items with low primary loadings and high secondary loadings are recommended procedures for conducting factor analyses (Hatcher, 1994; Thompson \& Daniel, 1996) and these procedures have been utilized in prior communication research (Frymier, Shulman, \& Houser, 1996; Myers \& Weber, 2004; Weber \& Patterson, 2000).

The factor analysis failed to produce the 4-factor solution proposed by Foster (2004); however, it did result in an interpretable 3-factor solution, with each factor comprised of six items (See Appendix A). After reviewing the items that loaded onto each factor, the three factors 
were named: (1) trivial gossip (i.e., gossiping to pass the time, idle "chit chat"), (2) influential gossip (i.e., gossiping to manipulate people), and (3) behavioral guidance gossip (i.e., using gossip as a guide to how individuals should act). To validate the new 18 -item scale, Study Two was conducted.

Study Two

Participants. Participants for this study consisted of a convenience sample of 218 college students (106 men, 111 women, one participant did not indicate sex) enrolled in an introductory communication course at a large mid-Atlantic university. The participants had a mean age of $19.82(S D=1.95)$. Participation in the study was voluntary and responses were kept anonymous.

Procedure. A second survey was completed by a new set of participants. The survey included the new 3-factor Gossip Functions Questionnaire, the Tendency to Gossip Questionnaire, the Indirect Interpersonal Aggressiveness measure, the 10-item Machiavellianism Scale, and a number of demographic questions.

3-Factor Gossip Functions Questionnaire. Each participant completed the new 18-item 3-Factor Gossip Functions Questionnaire (See Appendix A). Participants completed this scale using a five-point Likert-type scale that ranged from strongly disagree (1) to strongly agree (5). The mean, standard deviation, and alpha for the entire scale was: $M=50.97, S D=10.14, \alpha=$ 0.88. The means, standard deviations, and alphas for each of the subscales were: trivial gossip $(M=20.25, S D=4.78, \alpha=0.76)$, influential gossip $(M=13.14, S D=3.99, \alpha=0.75)$, and behavioral guidance gossip $(M=17.54, S D=3.98, \alpha=0.73)$.

Tendency to Gossip Questionnaire. A participant's propensity to use gossip was assessed using Nevo and Nevo's (1994) Tendency to Gossip Questionnaire (See Appendix B). Participants completed this 20-item scale using a seven-point Likert-type scale that ranges from 
almost never true (1) to almost always true (7). The mean, standard deviation, and alpha for the entire scale was: $M=65.87, S D=18.71, \alpha=0.90$. This mean, standard deviation, and alpha are consistent with previous research (Nevo \& Nevo, 1994).

Indirect Interpersonal Aggressiveness. Next, a participant's use of indirect interpersonal aggression was assessed using Beatty et al.’s (1999) 10-item Indirect Interpersonal Aggressiveness measure (1999) (See Appendix C). The participants completed this scale using a five-point Likert-type scale that ranges from almost never true (1) to almost always true (5). The mean, standard deviation, and alpha in this study were: $M=21.99, S D=8.19, \alpha=0.90$. This mean, standard deviation, and alpha are consistent with previous research (Beatty et al., 1999).

Machiavellianism. Lastly, a participant's level of Machiavellianism was assessed using Allsopp, Eysenck, and Eysenck’s (1991) 10-item Machiavellianism Scale (See Appendix D). Participants completed this scale using a seven-point Likert-type scale that ranges from strongly disagree (1) to strongly agree (7). The mean, standard deviation, and alpha were: $M=29.67, S D$ $=11.03, \alpha=0.88$. This mean, standard deviation, and alpha are consistent with previous research (Allsopp et al, 1991).

Data Analysis. In an attempt test Hypothesis one and to validate the three factors derived in Study One, responses to the 18-item 3-Factor Gossip Functions Questionnaire were subjected to a confirmatory factor analysis. Hypotheses two, three, and four were tested using Pearson correlations.

\section{Results}

Hypothesis one forwarded that the best fit for the GFQ would be a measurement model that has a 4-factor solution. Based on the EFA performed in Study One, the first hypothesis was rejected. However, three factors emerged from the EFA conducted in Study One. In order to test 
the new, 3-factor version of the GFQ, a CFA was performed using the CALIS procedure. The hypothesized model separated the new 18-item scale into three factors.

For the model, the Goodness of Fit Index (GFI), Comparative Fit Index (CFI), and the Non-normed Index (NNFI) were all below $0.90(0.82,0.73,0.73$ respectively). These values indicate that the measurement model did not provide a good fit to the data (Hatcher, 1994). Additionally, the model presented a significant chi-square test, and the degrees of freedom were more than a 2:1 ratio with the chi-square value $\left(\chi^{2}(132)=453.55, p<0.01\right)$. Based on the recommendation of Hatcher (1994), the 3-factor model of the GFQ is rejected. Although the confirmatory factor analysis did not reveal the three factors that were predicted, the responses to the 18-item, 3-factor Gossip Functions Questionnaire were used to answer the remaining hypotheses.

Hypothesis two stated that individuals high in indirect interpersonal aggression would be more likely to use all of the functions of gossip. Results of a Pearson correlation supported this hypothesis with individuals' level of indirect interpersonal aggression significantly correlating with the overall functions of gossip $(r=0.32, p<0.01$.

Hypothesis three stated that individuals high in Machiavellianism would be more likely to use all of the functions of gossip. Results of a Pearson correlation supported this hypothesis with individuals' level of Machiavellianism significantly correlating with the overall functions of $\operatorname{gossip}(r=0.40, p<0.01)$.

Hypothesis four stated that individuals with a high tendency to gossip will be more likely to use all of the functions of gossip. Results of a Pearson correlation supported this hypothesis with an individuals' tendency to gossip significantly correlating with the overall functions of $\operatorname{gossip}(r=0.52, p<0.01)$. 


\section{Discussion}

The primary goal of this study was to validate the Gossip Functions Questionnaire as a multi-dimensional measure for the reasons why people gossip (Foster, 2004). As the exploratory factor analysis revealed, the items from the GFQ failed to load onto their appropriate factors, providing a lack of support for the first hypothesis. However, the items did load onto three, conceptually sound, distinct factors. Following the collection of a second data set, a CFA was computed in order to confirm this 3-dimensional measurement model. The responses to the items failed to load onto their appropriate factors, and therefore, failed to provide evidence for the content validity for the scale. Although the factor analyses failed to provide evidence for its multi-dimensionality, responses from the GFQ were used to answer the last three hypotheses.

Hypothesis two was supported with individuals' level of indirect interpersonal aggression significantly correlating with the functions of gossip. This indicates that those who are high in indirect interpersonal aggression may use gossip as a means of indirectly attacking another individual. Hypothesis three was supported with individuals' level of Machiavellianism significantly correlating with the functions of gossip. This finding indicates that those high in the Machiavellianism trait may use gossip as a way of manipulating other people to do what they want. Finally, hypothesis four was also supported with an individuals' tendency to gossip significantly correlating with the functions of gossip. This finding indicates that individuals with a propensity to gossip are more likely to use each of the functions of gossip in their interactions with others.

While the exploratory and confirmatory factor analyses of the GFQ failed to produce the desired factors, the GFQ did attain significant correlations with other theoretically related variables. When examining the results of both studies as a whole, the evidence argues for 
construct validity while also having problems with content validity. The inability of the GFQ to retain a stable factor structure indicates a problem with the measure's content validity. However, the GFQ's relationship with other theoretically related variables (i.e., indirect interpersonal aggression, Machiavellianism, and tendency to gossip) provides evidence for its construct validity. The problem appears to be with the operationalization of the construct, rather than the construct itself. In other words, it is the dimensionality of the GFQ that should be questioned. Based on the relationships attained between the GFQ and indirect interpersonal aggression and Machiavellianism, there seems to be a strategic component to gossip such that respondents understand that there is an appropriate use for this type of communication. However, it is apparent that the original GFQ, as well as the revised GFQ tested in Study Two, are not able to accurately assess the specific functions or reasons why people use gossip. Therefore, the lack of content validity may be caused by the possibility that the GFQ does not measure the functions of gossip that it claims to measure. Although the GFQ failed to provide content validity, the construct of gossip should still be considered a communication phenomenon of interest to researchers.

As previously stated, the 3-factor GFQ's relationship with the personality traits of indirect interpersonal aggression and Machiavellianism continues to provide construct validity. Because this study assumed that the gossip construct would hold a negative connotation, the hypotheses forwarded relationships with other negatively viewed communication traits. The significant correlations that were found not only reinforced the belief that gossiping is, most often, seen as negative (Levin et al., 1988; Nicholson, 2001; Turner et al., 2003), they also provided evidence that the underlying construct of the GFQ was valid.

Another possible explanation for the positive relationships between the GFQ and indirect 
interpersonal aggression, Machiavellianism, and tendency to gossip might be due to a social desirability bias. There may be a significant difference in how individuals respond to the items on each of the measures as a result of how influenced they are by a social desirability bias. The negative connotation associated with gossip, aggression, and manipulation may have swayed the participants in the study to produce socially desirable responses. It is possible that those participants, who felt the need to answer in a socially desirable manner, were unwilling to report that they communicate using these negative traits. Whereas, those participants who were not as influenced by a social desirability bias may have felt more comfortable indicating that they communicate using gossip, indirect interpersonal aggression, or Machiavellianism. This explanation would indicate that the relationships found between the GFQ, TGQ, indirect interpersonal aggression, and Machiavellianism may simply be an artifact of individuals' tendency to respond to the items in a socially desirable way.

Although the results of the correlations confirm the hypotheses and can be seen as evidence for construct validity, reservations should be given to any results garnered in this study because of the obvious measurement issues. The results of the exploratory and confirmatory factor analyses failed to uncover a stable factor structure, therefore the utility of the GFQ is called into question. A separate limitation to this study is that only negative communication traits were used to validate the GFQ. As a number of authors suggest, positive, or socially sanctioned, gossip also exists (Foster, 2004; Levin et al., 1988; Turner et al., 2003) and, therefore, should be examined in relation to positive communication traits. The majority of the items for both the TGQ and the GFQ are not worded to include gossip dealing with socially approved behavior, limiting the usefulness and generalizability of the measures.

Future research should strive to overcome the limitations previously addressed. First, 
researchers should consider the relationship between gossip and positive personality and communication traits. Individuals who are high in self-monitoring or communication competence may have the ability to use gossip appropriately and positively. Second, future research concerning gossip should determine if a social desirability bias exists. It is possible to collect data in order to determine the influence that social desirability has on participant responses. By statistically controlling for this bias, the influence of this effect on the relationships between the variables of interest can be removed. Third, additional work should be done to refine the operationalization of the gossip construct. Before research can determine if gossip serves different functions in communication, it is imperative to have a valid multidimensional instrument. 


\section{References}

Allsopp, J., Eysenck, H. J., \& Eysenck, S. B. G. (1991). Machiavellianism as a component in psychoticism and extraversion. Personality and Individual Differences, 12, 29-41.

Beatty, M. J., Valencic, K. M., Rudd J. E., \& Dobos J. A. (1999). A “dark side” of communication avoidance: Indirect verbal aggressiveness. Communication Research Reports, 16, 103-109.

Bergmann, J. R. (1993). Discreet indiscretions: The social organization of gossip. New York: Aldine de Gruyter.

Blumstein, P. W. (1973). Audience, machiavellianism, and tactics of identity bargaining. Sociometry, 36, 346-365.

Burgoon, M. (1971). The relationship between willingness to manipulate others and success in two different types of basic speech communication courses. Speech Teacher, 20, 178-183.

Cayanus, J. L., Martin, M. M., \& Weber, K. D. (in press). The relationship between driver anger and aggressive communication traits. Communication Research Reports.

Chesebro, J. L., \& Martin, M. M. (2003). The relationship between conversational sensitivity, cognitive flexibility, verbal aggressiveness and indirect verbal aggressiveness. Communication Research Reports, 20, 143-150.

Christie, R., \& Geis, F. L. (1970). Studies in Machiavellianism. New York: Academic Press.

Cooley, C. H. (1962). Social organization. New York: Schocken Books.

Dunbar, R. I. M. (2004). Gossip in evolutionary perspective. Review of General Psychology, $8,100-110$.

Dunbar, R. I. M, Duncan, N. D. C., \& Marriott, A. (1997). Human conversational behavior. 
Human Nature, 8, 231-246.

Falbo, T. (1977). Multidimensional scaling of power strategies. Journal of Personality and Social Psychology, 35, 537-547.

Foster, E. K. (2004). Research on gossip: Taxonomy, methods, and future directions. Review of General Psychology, 8, 78-99.

Foster, E. K., \& Rosnow, R. L. (2005). Gossip and network relationships. Manuscript submitted for publication.

Frey, L. R., Botan, C. H., \& Kreps, G. L. (2000). Investigating communication: An introduction to research methods ( $2^{\text {nd }}$ ed.). Boston: Allyn and Bacon.

Frymier, A. B., Shulman, G. M., \& Houser, M. (1996). The development of a learner empowerment measure. Communication Education, 45, 181-199.

Hatcher, L. (1994). A step-by-step approach to using the SAS system for factor analysis and structural equation modeling. Cary, NC: SAS Institute.

Hovland, C. I., \& Weiss, W. (1951). The influence of source credibility on communication effectiveness. Public Opinion Quarterly, 15, 635-650.

Khattree, R., \& Naik, D. N. (2000). Multivariate data reduction and discrimination with SAS software. Cary, NC: SAS Institute.

Knapp, R. H. (1944). A psychology of rumor. Public Opinion Quarterly, 8, 22-37.

Kuttler, A. F., Parker, J. G., \& La Greca, A. M. (2002). Developmental and gender differences in preadolescents' judgments of the veracity of gossip. Merrill-Palmer Quarterly, 48, 105-132.

Levin, J., Mody-Desbareau, A., \& Arluke, A. (1988). The gossip tabloid as agent of social control. Journalism Quarterly, 65, 514-517. 
Lilienfeld, S. O. (1996). The MMPI-2 antisocial practices content scale: Construct validity and comparison with the psychopathic deviate scale. Psychological Assessment, 8, 281-293.

Martin, M. M., \& Valencic, K. M. (April, 2002). The relationship between indirect verbal aggression and verbal aggression, cognitive flexibility, assertiveness, responsiveness, machiavellianism, and communication apprehension. Paper presented at the meeting of the Eastern Communication Association, New York City, NY.

McHoskey, J. W. (1995). Narcissism and machiavellianism. Psychological Reports, 77, $755-759$

Mudrack, P. E., \& Mason, E. S. (1995). Extending the Machiavellianism construct: A brief measure and some unexplored relationships. Journal of Social Behavior and Personality, 10, 187-200.

Myers, S. A., \& Weber, K. D. (2004). Preliminary development of a measure of sibling relational maintenance behaviors: Scale development and initial findings. Communication Quarterly, 52, 1-13.

Nevo, O, \& Nevo, B. (1993). Gossip and counseling: The tendency to gossip and its relation to vocational interests. Counseling Psychology Quarterly, 6, 229-239.

Nevo, O., Nevo, B., \& Derech-Zehavi, A. (1994). The tendency to gossip as a psychological disposition: Constructing a measure and validating it. In B. F. Goodman \& A. Ben-Ze'ev (Eds.), Good gossip (pp. 180-189). Mahwah, NJ: Erlbaum Nicholson, N. (2001). The new word on gossip. Psychology Today, 34, 41-45. Rosnow, R. L., \& Fine, G. A. (1976). Rumor and gossip: The social psychology of hearsay. New York: Elsevier. 
Rysman, A. (1977). How the "gossip" became a woman. Journal of Communication, 27, 176-180.

Singleton, R. A., Jr., \& Straits, B. C. (1999). Approaches to social research $\left(3^{\text {rd }}\right.$ ed.). New York: Oxford University Press.

Spacks, P. M. (1982). In praise of gossip. Hudson Review, 35, 19-38.

Stirling, R. B. (1956). Some psychological mechanisms operative in gossip. Social Forces, $34,262-267$.

Thompson, B., \& Daniel, L. G. (1996). Factor analytic evidence for the construct validity of scores: A historical overview and some guidelines. Educational and Psychological Measurement, 56, 197-208.

Turner, M. M., Mazur, M. A., Wendel, N., \& Winslow, R. (2003). Relational ruin of social glue? The joint effect of relationship type and gossip valence on liking, trust, and expertise. Communication Monographs, 70, 129-141.

Weber, K., \& Patterson, B. R. (2000). Student interest, empowerment, and motivation. Communication Research Reports, 17, 59-70.

Wert, S. R., \& Salovey, P. (2004). Introduction to the special issue on gossip. Review of General Psychology, 8, 76-77.

Widgery, R. N., \& Ruch, R. S. (1981). Beauty and the machiavellian. Communication Quarterly, 29, 297-301.

Wilson, D. S., Near, D., \& Miller, R. R. (1996). Machiavellianism: A synthesis of the evolutionary and psychological literatures. Psychological Bulletin, 119, 285-299. 
Appendix A

Factor Loadings of the 3-Factor Gossip Functions Questionnaire

Scale Item
Factor $^{\mathrm{a}}$

2

1. Listening to people's opinions of others helps me better judge aspects of my own life.

2. I can't stand being around people who talk about other people behind their backs.

3. It is OK to tell a new person in my circle what it was about someone who is gone that no one liked.

4. It's fair to say that talking about other people tells us what to do, that is, how to behave in a lot of situations.

$\begin{array}{ccc}-.15 & .51 * & .01 \\ .22 & .65^{*} & .12\end{array}$

5. Hearing gossip about others could help me avoid saying or doing the wrong thing.

6. When someone does something inappropriate, I gossip about it so the person will be less likely to do it again.

7. It is OK to gossip with new person in my circle what it was about someone who is gone that no one liked.

$\begin{array}{ccc}.01 & -.11 & .67 * \\ -.02 & .66^{*} & -.03 \\ .19 & .66^{*} & -.04\end{array}$

8. Some of my friendships were formed in part by gossiping.

9. I like to talk about people at times. 10. With good friends, I tend to share information I've heard about others.

11. For me, there's nothing enjoyable about gossiping.

12. I can't understand why people get so much pleasure out of talking about people.

13. I can't stand being around people who gossip.

14. I gossip to make and maintain friendships. 15. I gossip to influence others.

16. It's fair to say that gossip tells us what to do, that is, how to behave in a lot of situations.

$\begin{array}{lll}.06 & .02 & .51^{*} \\ .09 & -.19 & .76^{*}\end{array}$

17. Gossiping helps me better judge aspects of my own life.

18. I gossip, primarily, for entertainment.

\begin{tabular}{ccc}
.01 & .20 & $.58^{*}$ \\
$.55 *$ & .16 & .08 \\
& & \\
$.68 *$ & .08 & .03 \\
& & \\
$.71 *$ & -.04 & -.07 \\
& & \\
$.74 *$ & -.04 & .02 \\
& & \\
$.80 *$ & -16 & .03 \\
-.06 & .15 & $.67 *$ \\
-.01 & .24 & $.64 *$ \\
& & \\
& & \\
-.06 & $.78 *$ & .05 \\
& & \\
-.04 & $.67 *$ & .11 \\
$.52 *$ & .15 & .16 \\
\hline 5.81 & 1.74 & 1.16 \\
65.00 & 19.00 & 13.00 \\
.76 & .73 & .75
\end{tabular}

Note. ${ }^{\text {a }} 1=$ trivial, 2 = behavioral guide, $3=$ influence $*=$ primary loading 


\section{Appendix B}

\section{Tendency to Gossip Questionnaire}

(Nevo \& Nevo, 1994)

Instructions: Read the statements below carefully, and try to estimate the extent to which they apply to your own behavior. Circle the number that fits your behavior for each item on the questionnaire.

\section{$\begin{array}{lllllllll}\text { Almost never true } & 1 & 2 & 3 & 4 & 5 & 6 & 7 & \text { Almost always true }\end{array}$}

1. I I r r r gossip columns in newspapers.

2. I l like talking to friends about other people's clothes.

3. I I I tend to talk with my friends about relationships between men and women.

4. I I prefer listening to conversations about other people rather than taking part in them.

5. I I I tend to gossip with a good friend about people who have left the country.

6. I like talking to friends about other people's grades and intellectual achievements.

7. I I I think that I can contribute interesting information to almost any conversation about people.

8. I I I tend to talk to friends about the problems some of our friends have at work.

9._I l like analyzing with a friend the compatibility of various couples.

10. I I like talking with a friend about the personal appearance of other people.

11. I I tend to talk with friends about the educational level of people we know in important positions.

12. I enjoy analyzing with my friends the motives and reasons for other people's behaviors.

13. I like talking with a friend about the salaries of our mutual friends.

14. When I come back from a party or some other event, I tend to talk about my impressions of the personal appearance of the others who were there.

15. I I I tend to talk to friends about the success of certain people in their jobs.

16. Usually, I feel I know what is going on, who is going out with whom, etc.

17. I tend to talk with friends about the love affairs of people we know.

18. I I like reading biographies of famous people.

19. I I l like to tell friends interesting details concerning other people.

20. I__ I tend to gossip 


\section{Appendix C}

\section{Measure of Indirect Interpersonal Aggression \\ (Beatty, Valencic, Rudd, \& Dobos, 1999)}

Instructions: Read the statements below carefully, and try to estimate the extent to which they apply to your own behavior. Circle the number that fits your behavior for each item on the questionnaire.

\section{$\begin{array}{lllllll}\text { Almost never true } & 1 & 2 & 3 & 4 & 5 & \text { Almost always true }\end{array}$}

1. If someone intentionally treats me unfairly, I would spread rumors about him or her.

2. I I would provide inaccurate information to a person who has been hostile or unfair to me.

3. I I might "forget" to relay information to a person who has been hostile or unfair to me.

4. I I I would work "behind the scenes" to keep an enemy from getting what he or she wants.

5. If someone is a real jerk, I would harm his or her chances for success if given the chance.

6. I__ I would facilitate the failure of people who have mistreated me.

7. G__ Given the chance, I would keep a person who has mistreated me from getting a job or promotion that he or she really wants.

8.___ I would not warn a person who has mistreated me about a problem situation even though my information would allow him or her to avoid trouble.

9.___ I have destroyed one or more of another's belongings because he or she mistreated me.

10. I _ I would try to keep important information from people who have been hostile toward me. 


\section{Appendix D}

Machiavellianism Scale

(Allsopp, Eysenck, \& Eysenck, 1991)

Instructions: Read the statements below carefully, and try to estimate the extent to which you agree with each statement. Circle the number that fits your level of agreement.

$\begin{array}{lllllllll}\text { Strongly disagree } & 1 & 2 & 3 & 4 & 5 & 6 & 7 & \text { Strongly agree }\end{array}$

1. Would you be prepared to deceive someone completely if it were to your advantage to do so?

2. W__ Would you be prepared to do a bad turn to someone in order to get something you particularly wanted for yourself?

3. D__ Do you often act in a cunning way in order to get what you want?

4. Would you be prepared to "walk all over people" to get what you want?

$5 . \quad$ Do you enjoy manipulating people?

6. D__ Do you tend to do most things with an eye to your own advantage?

7.___ Do you agree that the most important thing in life is winning?

8. Would you be prepared to be quite ruthless in order to get ahead in your job?

9. Would you be prepared to be humble and honest rather than important and dishonest?

10 ___ Would you like to be very powerful? 